\title{
The economic resilience of amenity cluster in the post-Covid city : the effect of relatedness on the survival of amenity shops
}

\author{
Bogang Jun ${ }^{\mathrm{a}, \mathrm{d}, 1, *}$, C. Jara-Figueroa ${ }^{\mathrm{b}}$, Donghyeon $\mathrm{Yu}^{\mathrm{c}, \mathrm{d}, 2, * *}$ \\ ${ }^{a}$ Department of Economics, Inha University, Incheon, South Korea \\ ${ }^{b}$ MIT Media Lab, Massachusetts Institute of Technology \\ ${ }^{c}$ Department of Statistics, Inha University, Incheon, South Korea \\ ${ }^{d}$ Department of Data Science, Inha University, Incheon, South Korea
}

\begin{abstract}
Amenity clusters that consist of coffee shops, restaurants, and other small businesses provide utility to urban life and jobs for city dwellers. While most small business clusters were hard hit by the restrictions imposed during the COVID-19 pandemic, others were able to adapt. What determines the economic resilience of amenity clusters? By using store-location data for Seoul during 2016-2021, we identify spatial clusters of amenities and an amenity space to examine the effect of relatedness on the resilience of each cluster. We find that businesses are more likely to survive when located in clusters of related amenities.
\end{abstract}

Keywords: Resilience, Amenity space, Relatedness

\section{Introduction}

During the COVID-19 outbreak, as governments restricted mobility, workers who could transition to remote work did so. Yet, for those workers in service-oriented industries that relied on business from the local clientele, remote work was not really an option. Restaurants, coffee shops, and other small businesses quickly tried to reinvent themselves by investing in protective equipment, contactless payment methods, and delivery services. As the world slowly reopens and people timidly venture to these clusters of local amenities, one thing has become clear; while some clusters were not there anymore, others showed strong resilience in the face of adverse economic conditions.

The topic of economic resilience has been studied extensively in Economic Geography at different scales (Christopherson et al., 2010; Martin and Sunley, 2015; Evans and Karecha, 2014 Cowell 2013). Although there is no widely accepted definition, the economic resilience of regions tend to be loosely defined as the region's ability to adapt to changing economic conditions. Common examples of resilient cities are those of the San Francisco Bay Area (Saxenian, 1996), New York City (Jacobs et al. . 1970), and Munich Evans and Karecha (2014). Case studies focusing on specific cities have highlighted the complex interplay among political systems, strong urban system, city-level leadership, and entrepreneurship Evans and Karecha (2014); Cowell

\footnotetext{
*Corresponding: bogang.jun@inha.ac.kr

${ }^{* *}$ Corresponding: dyu@inha.ac.kr

Preprint submitted to SocArXiv
}

September 1, 2021 
(2013). Notably, Simmie and Martin (2010) compare the 45-year growth path of Cambridge and Swansea in the UK from an evolutionary perspective. Their analysis suggests that the key factors that determine resilience are endogenous sources of new knowledge with a combination of market-driven and entrepreneur decisions.

On the empirical side, Doran and Fingleton (2018) analyse the differential impact of the 2008 financial crisis across US metropolitan areas to analyse the effect of a city's economic structure on resilience. They find that more specialized areas are less resilient to the shock than more diversified areas, but that specialization can increase the rate of recovery after the crisis. Moreover, they find a positive impact of structural change on the recoverability of areas. Glaeser et al. (2014) analyse the 200-years regional history of Eastern US cities and argue that regional changes can be best understood as a set of responses by people and firms to technological change.

The empirics of measuring industrial structure and technological change have advanced deeply in the past decades in the fields of economic complexity, regional studies, and evolutionary economic geography. By looking at the co-exporting of products (Hidalgo et al., 2007, Jun et al. 2020) or co-location of industries (Neffke et al., 2011, Gao et al., 2017) and technology (Kogler et al., 2013, Rigby, 2015; Balland et al., 2019, Kim et al., 2021), scholars can generate the network structure of those product or industries and predict the probability of success in entering a new activities of countries or regions based on their foot-print on the network. They show that countries, regions, cities, and firms are more likely to successfully enter a new activities, such as new product, new industry, new technology, and new knowledge, when they already have the related activities in them (Boschma et al., 2015, 2013; Frenken et al., 2007. Hidalgo et al., 2007, Jara-Figueroa et al. 2018, Jun et al. , 2020, Neffke et al., 2011; Kogler et al. 2013; Gao et al. 2017; Kim et al. 2021; Balland et al., 2019). Their empirical findings are formalized as the Principle of Relatedness (Hidalgo et al. 2018).

Only recently, complexity scholars have started to look at the intra-city scale by focusing on clusters of amenities within cities, as opposed to the entire city. By using location data for more than a million stores (restaurants, laundromats, museums, hospitals, etc.), Hidalgo et al. (2020) build the amenity space, which is a network structure connecting 95 different types of amenities, based on the collocation of amenities in clusters. To build this amenity space, the authors identify amenity clusters using a novel spatial clustering algorithm, designed specifically to detect amenity-dense neighborhoods. They show that their relatedness measure based on the amenity space predicts the evolution of the cluster. Specifically, new types of amenities show up in clusters dense with related amenities.

Given the documented importance of relatedness in the evolution of local clusters of businesses, and given the emphasis of regions' industrial structures on their economic resilience, we focus on the link between relatedness and resilience at the micro-geographic scale. Specifically, we ask if businesses located in clusters dense with related activities were more likely to survive the COVID-19 pandemic.

Here, we contribute to the literature on economic geography and economic complexity by using more than 1.8 million store location data of Seoul, South Korea over the period 20162021. This period includes the pandemic crisis that started in early $202 q^{1}$ and it allows us to examine the effect of COVID-19 on the survival of local businesses and clusters of amenities. Considering that Korea haven't had lockdown or border closure during the pandemic, consumers have been able to choose where they visit to buy. Therefore, our data allow us to examine the

${ }^{1}$ In Korea, the first confirmed case was at Jan 8th, 2020 and the first wave of pandemic was in Feb 2020 
phenomena deriving from consumers' own decision, rather than government control. Despite of no-lockdown in Korea, however, Korean Government implemented social-distancing policy, which regulates the size of public/private assemblies and the operating hour of stores, and this policy gave a harmful effect on amenity stores. Under the same policy, while most small business clusters were hard hit by the restrictions imposed during the COVID-19 pandemic, others were able to adapt. What determines the economic resilience of amenity clusters?

First, we identify our spatial unit of analysis (i.e. the amenity clusters) by using the clustering detection algorithm introduced in Hidalgo et al. $(2020)$. Then, by looking at the co-location of amenities in clusters, we build the amenity space, a network of related amenity categories. Based on this structure, we examine (i) whether a cluster is likely to increase its number of amenities in a given category as a function of the density of related amenities (cluster-level analysis) and (ii) whether the survival rate of individual stores increases surrounded by other related amenities (store-level analysis). First, we find that the number of new amenities in each cluster in a given category increases when the cluster already has more related amenity stores in them. This confirms the result already documented by Hidalgo et al. (2020). Second, we find that individual stores are more likely to survive during the pandemic era, when located in clusters that are dense with related amenities. This last finding is crucial, as it extends the results known about resilience at a macro scale to the microgeographic level.

The rest of this paper is organized as follows: Section 2 summarizes the data and methods. Section 3 presents the two main results of this work. First, we confirm for Korea the known fact about the evolution of amenity clusters in the US. Second, we document that businesses in clusters of related amenities were more likely to survive the COVID-19 pandemic. Finally, Section 4 concludes.

\section{Method}

\subsection{Data}

We use store-location data including latitude and longitude compiled by the Korean Small Enterprise and Market Service between 2016 and 2021. These data provide information regarding every small enterprises operating in Korea belonging to one of the following categories: travel/leisure/entertainment, real-estate, retail, accommodation, sports facilities, restaurants, other living-related services, health, and education. The information that these data provides includes the name of the store, address, geolocation, and the types of amenities provided by the small enterprises. Given that the focus of the Korean Small Enterprise and Market Service is to helps small businesses open and survive, most department stores or big marts are excluded.

Amenity in the dataset is classified according to the Small Business Market Promotion Corporation/Commercial Information Industry Code. There are 9, 94, and 693 large, medium, and small categories, respectively, in the classification. This differs from Hidalgo et al. (2020), as our data does not include amenities like national parks, and airports, as well as amenities related to religion that have public aspects. As seen in the classification, our data includes all amenities that can be provided by small businesses.

While our store location data covers all cities in Korea, we focus on Seoul for our analysis. The number of stores in Seoul are 362,340, 330,089, 401,071, 370,321, 345,268 in each year from 2017 to 2021, and our unit of analysis is "individual store-detected cluster-amenity type" in the mid-level classification. Using the mid-level classification allows us to better capture consumer behavior. 
For control variables, we also use data from the Census on Establishments. These data partially overlap with our main data, which is store location data, but it provides a broader range of organizations in Korea, including firms, unincorporated private enterprises, non-profit organization, and all types of government organizations; and different types of information, including number of employees and gender of owner or CEO, although this census data does not provide geolocation of each enterprise. Further, the census data does not allow us to access the name of each individual enterprise, so we cannot track the survival of each enterprises over time. Since this data allow us to access their location at the donglevel (similar scale with municipality in the US), we use the number of all employees and the number of enterprises as our control variables after matching locational information to our individual store data at donglevel.

We also use datasets from Seoul Open Data Plaza to control for regions' population, population density, aging index, and share of lowest income group. These variables are also dong-level information.

\subsection{Finding amenity clusters: the spatial unit of analysis}

Does the existence of related amenity shops predict the survival rate of each shop? How does the amenity structure support the cluster while facing exogenous shock? To explore these questions, we firstly need to identify amenity clusters in the city. One can say that administrative districts may serve as our spatial unit of analysis, but they do not bind our daily consumption life in a city, since we are unaware of the administrative borders within the city. Therefore, we try to identify the spatial boundaries of consumption by using locations of stores, which helps reveal spatial consumption patterns in a city, instead of using administrative boundaries.

Following Hidalgo et al. (2020), we begin with identifying amenity-dense neighborhoods by calculating the effective number of amenities, $A_{i}$, for every location of small businesses $i$ that provides amenities to a city with the following equation:

$$
A_{i}=\sum_{j=1}^{N} e^{-\gamma d_{i j}}
$$

where $N$ is the total number of stores in the city, $d_{i j}$ is the geodesic distance between store $i$ and store $j$, and $\gamma$ is a decay parameter for discounting stores that are located far away from the store $i$. As demonstrated in Hidalgo et al. (2020), the effective number $A_{i}$ decays by a half every $\ln (2) / \gamma \mathrm{km}$. Here, we set $\gamma=7.58$, which implies that the contribution of an amenity halves every $91.44 \mathrm{~m}$ and becomes 0.0022 at around $804.7 \mathrm{~m}(0.5 \mathrm{mile})$, which is the median of daily walking trip distance and its walking duration is around 10 minute (Yang and Diez-Roux 2012). Thus, $A_{i}$ can be considered as a centrality score of the shop $i$ that summarizes the number of shops located within 10-minute walking distance from the shop $i$.

After calculating the effective number of all stores $i$ in a city, we can find the local peak of $A_{i}$ on the map of city. Then, regarding the local peak as the center of the cluster, we allocate other stores to the cluster using an iterative greedy procedure as the radius of the cluster increases, following the suggested algorithm by Hidalgo et al. (2020). In this way, we identify 523 amenity clusters in Seoul. Considering that the area of Seoul is $605.2 \mathrm{~km}^{2}$, the area of an amenity cluster is approximately $1.15 \mathrm{~km}^{2}$, but in reality the effective area of the center of the cluster is smaller than $500 \mathrm{~m}$, because there are relatively smaller number of stores as the distance from the center increases and we also ignore stores that are far from the center. After identifying amenity clusters based on store location data in 2018, we use it as our spatial unit of analysis meaning that we track the changes in each clusters and each store based on the detected spatial boundary. 


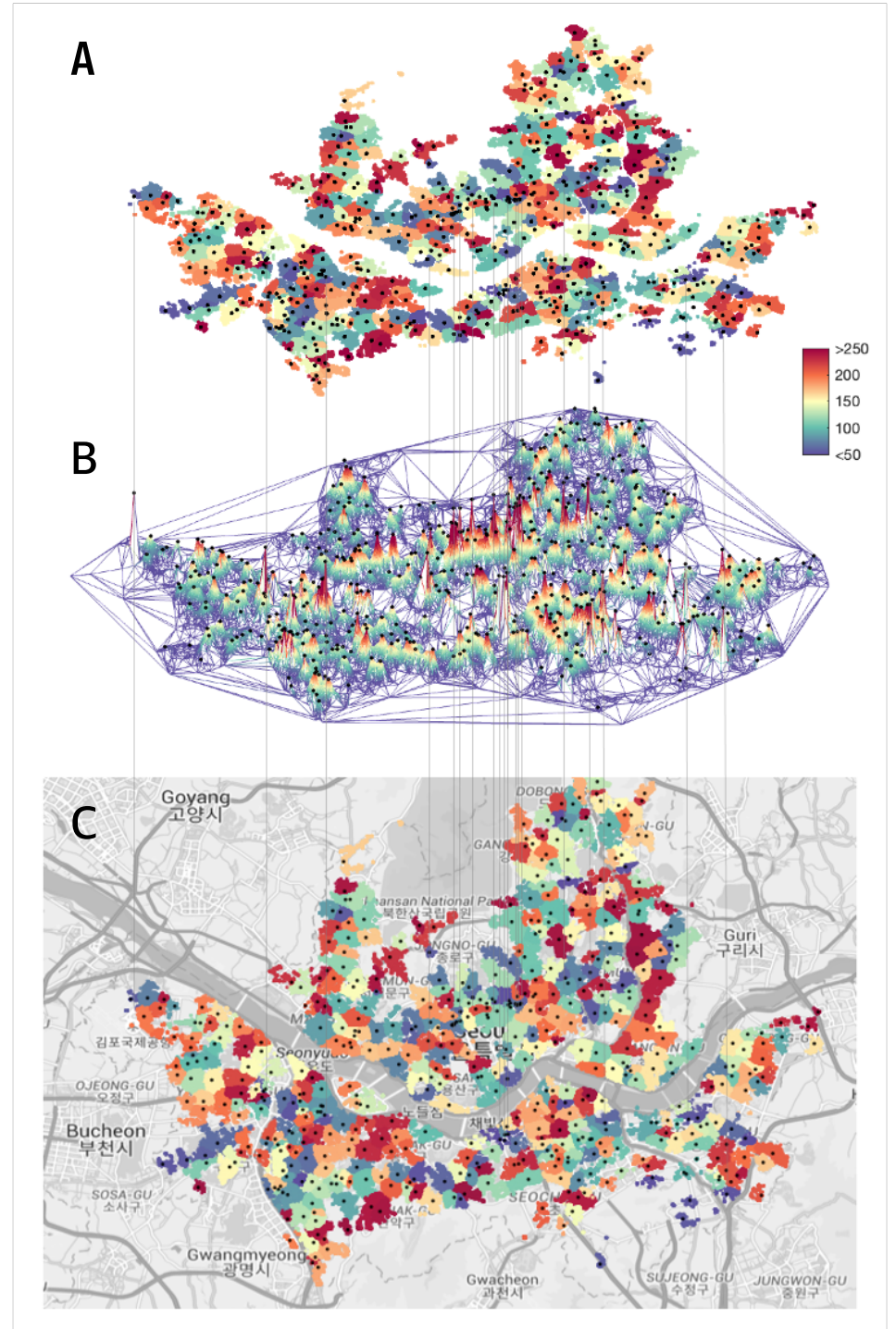

Figure 1. Amenity clusters in Seoul (A) Geolocational boundary of amenity clusters in Seoul depicted in different colors. (B) The number of effective amenities at each location. Color represents the level of the effective number, such that higher effective amenity is shown in red, while lower levels are depicted by blue. (C) Boundary of clusters is assigned to a location on the map of Seoul. Neighborhood centers are marked by black dots.

Figure 1(A)-(C) depict the method for identifying clusters and the clusters in Seoul. Figure 1 (A) shows the detected clusters and (B) shows the peaks and valleys of the effective number of amenities $A_{i}$, while (C) shows the projection of the clusters on the map of Seoul. The effective 
number of amenities $A_{i}$ reveal that the top 3 amenity-dense neighborhoods are around JW marriot Dongdaemun Square Seoul, around Express Bus Terminal, and the area between Jongno 3 ga and Jongno 4 ga, which are well-known amenity-dense areas.

\subsection{Amenity space and relatedness}

Identified amenity clusters allow us to build amenity space by looking at the co-location of amenities. As Hidalgo et al. (2020) stated, the amenity space is a network connecting amenities that are likely to co-locate in the same clusters. To capture the significant number of stores that provide amenity $a$ in a cluster $c$, we calculate the revealed comparative advantage (RCA) of cluster $c$ with amenity $a$ following Balassa (1965):

$$
R C A_{c, a}=\frac{x_{c, a}}{\sum_{i} x_{c, a}} / \frac{\sum_{c} x_{c, a}}{\sum_{c, a} x_{c, a}}
$$

where $x_{c a}$ is the number of stores that provides amenity $a$ in cluster $c$. 2007):

Using the result of $R C A$, we measure the proximity between amenity $a$ and $a^{\prime}$ (Hidalgo et al.

$$
\phi_{a, a^{\prime}}=\min \left\{P\left(R C A_{a} \mid R C A_{a^{\prime}}\right), P\left(R C A_{a^{\prime}} \mid R C A_{a}\right)\right\}
$$

When we create the amenity space of Seoul, we use store location data in 2018 , since this is pre-pandemic. We can create $94 \times 94$ proximity matrix of amenities using the mid-level classification and create $693 \times 693$ proximity matrix using the small-level classification. Figure 2 shows the amenity space of Seoul in 2018. While we use the small-level classification code in calculating relatedness, we show amenity space using the mid-level classification.

Figure 2 represents the spatial structure of Seoul. We can observe that the big cluster of retailers at the center and some types of retailers connect different functions across the city. At the upper right corner, amenities that we can mostly observe around residential areas, such as hair shop, laundromats, repair of home electronic goods, bakery, Korean spa, fried chicken, secondhanded goods, and private schools are observed, connected through the food retailer store. At the bottom, a general retail store connects amenities for lifetime events and tourism, such as hotel, wedding hall, car rental, general rental service, and buffet. A health and beauty supplement retail shop connects clinic and hospital, recruitment agency and entertainment pub.

Based on the proximity among amenities with a small-level classification, we construct the measure of relatedness $\omega_{c, a}$. The formula indicates a weighted average of the number of related amenities that are running in a cluster. Here, weights are the proximity between amenities $a$ and $a^{\prime}, \phi_{a, a^{\prime}}$, implying the minimum of the conditional probability that two amenities are collocated in same cluster and the consumer's utility gain from getting various related choices when they visit a certain amenity cluster. Formally, the measure of relatedness is given by:

$$
\omega_{c, a}=\sum_{a^{\prime}} \frac{\phi_{a, a^{\prime}}}{\phi_{a}} \cdot \frac{x_{c, a^{\prime}}}{x_{c}}
$$

where $\phi_{a, a^{\prime}}$ is the proximity between amenity $a$ and $a^{\prime}, x_{c, a}$ is the number of stores that provide amenity $a$ in cluster $c$. 


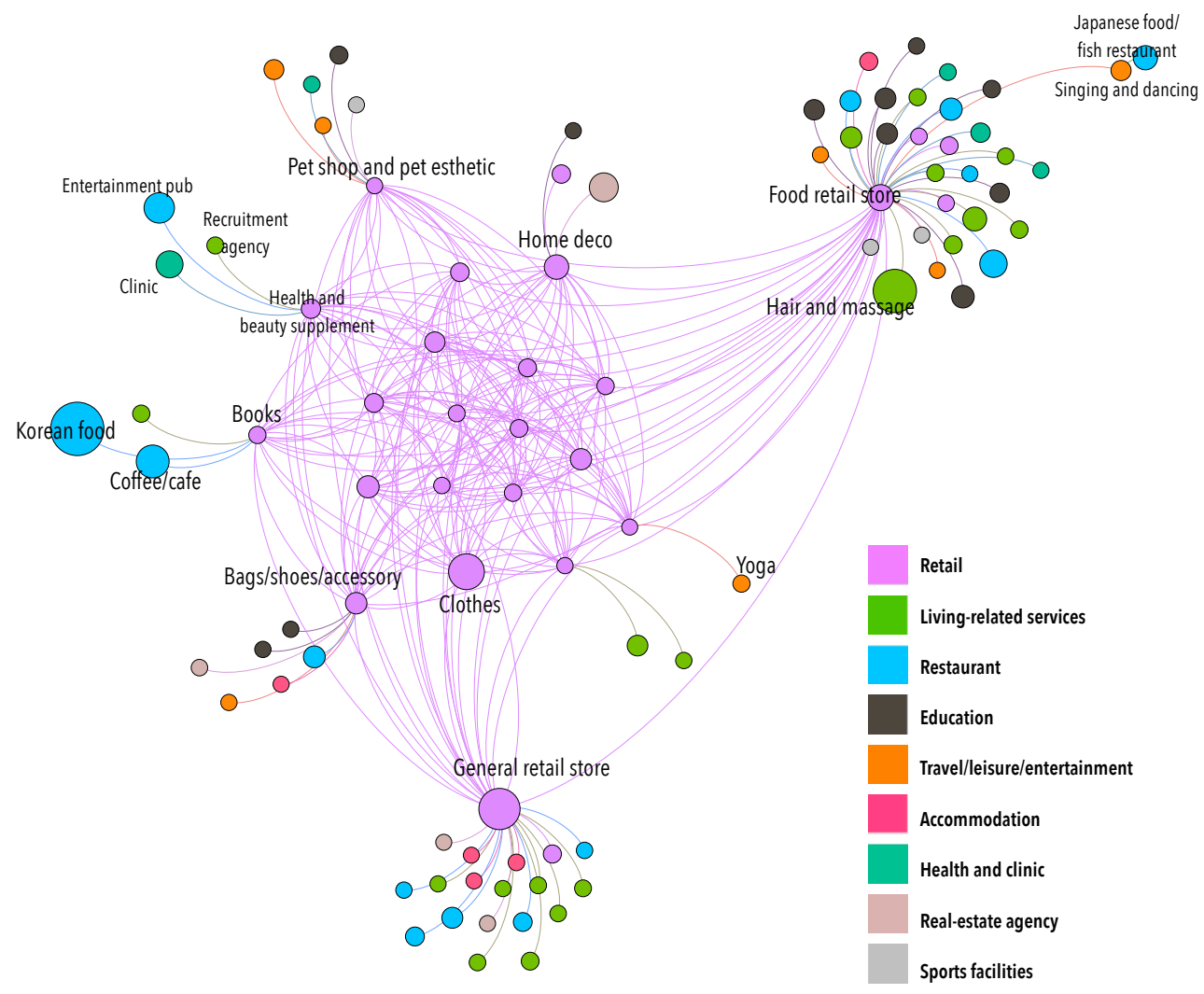

Figure 2. Amenity space of Seoul using mid-level classification of Small Business Market Promotion Corporation/Commercial Information Industry Code. Color represents types of amenities in large-level classification, while size of the node represents the number of shops in that amenity in Seoul

\section{Results}

3.1. Cluster level analysis: does relatedness help amenity clusters increase their number of shops?

According to the research stream on Principle of relatedness, countries, regions, and cities are more likely successfully enter a new activity, when they are already active in related activities in them (Hidalgo et al., 2018; Jara-Figueroa et al. 2018; Boschma et al., 2015; Neffke et al., 2011; Frenken et al., 2007; Hidalgo et al., 2007). Jun et al. (2020) examine the impact of relatedness on the increase of intensive margin in bilateral trade, instead of entering a new activity, and find that relatedness has a positive effect on the increase of intensive margin in bilateral trade.

Here, before moving on to checking the role of relatedness on the survival of amenity stores during the pandemic era in session 3.2. we examine whether the principle of relatedness holds in our amenity clusters by using our measure of relatedness $\omega_{c, a}$. Although Hidalgo et al. (2020) 
builds a parsimonious recommendation system that uses the relatedness of each amenity, the system focuses on the effect of entering a new activity for each amenity and does not check the overall general effect. Therefore, we examine the general effect of relatedness while controlling for the idiosyncratic characteristics of each region and amenity. Since our data explains a highly saturated metropolitan area, we cannot find many cases of entering a new activity. Moreover, because our interest is not in the regional development through diversification of amenities, but on the resilience of amenity clusters during the pandemic period, we check the effect of relatedness on the increase of intensive margin of cluster. Is a commercial cluster likely to increase the number of shops that provide an amenity in the cluster, when the cluster has more related amenities? Further, does the predictability hold even with the external shock, such as COVID-19? To answer this question, we construct our first empirical specificationas follows:

$$
\Delta x_{c, a, t+2}=\beta_{0}+\beta_{1} \omega_{c, a, t}+\beta_{2} x_{c, a, t}+\beta_{3} x_{c, t}+\mu_{c}+\lambda_{t}+\eta_{a}+\varepsilon_{c, a, t}
$$

where $\Delta x_{c, a, t+2}$ is the difference in the number of stores that provide amenity $a$ in cluster $c$ between time $t$ and $t+2, x_{c, a, t}$ is the number of stores that provide amenity $a$ in cluster $c$ at time $t$, and $x_{c, t}$ is the total number of stores with the same amenity (i.e., $x_{c, t}=\sum_{a} x_{c, a, t}$ ). $\mu_{c}$ is cluster fixed effect, which controls for time-invariant idiosyncratic characteristics of each amenity cluster, such as clusters of markets targeting Chinese tourists, embracing a central station of high-speed rail, or hip places for youngsters. Since each cluster's label has an effect on the decision process of consumers, controlling for each cluster's time-invariant characteristics is required. We also control for amenity fixed effect using its largest amenity classification (There are nine categories in the largest classification). In the pooled regression (column (5)), we have also included time-fixed effects so that our result can control for national time trend.

Table 1. The number of stores after one year for each year (column (1)-(4)) and all years (column (5)) during the periods 2016 - 2021, column (1) and (2) capture the effect of relatedness before the outbreak of COVID-19, while column (3) and (4) capture the effect after the COVID-19.

\begin{tabular}{lccccc}
\hline \hline & \multicolumn{5}{c}{ Dependent variable: $\Delta$ store $_{c, a, t+2}$} \\
\cline { 2 - 6 } & $2016-2018$ & $2017-2019$ & $2018-2020$ & $2019-2021$ & $2016-2021$ \\
& $(1)$ & $(2)$ & $(3)$ & $(4)$ & $(5)$ \\
\hline$\omega_{c, a, t}$ & $0.011^{* * *}$ & $0.042^{* * *}$ & -0.0003 & $-0.002^{* *}$ & $0.015^{* * *}$ \\
& $(0.001)$ & $(0.002)$ & $(0.001)$ & $(0.001)$ & $(0.001)$ \\
& & & & & \\
$x_{c, a, t}$ & $-0.375^{* * *}$ & $-0.158^{* * *}$ & $0.101^{* * *}$ & $-0.231^{* * *}$ & $-0.197^{* * *}$ \\
& $(0.001)$ & $(0.001)$ & $(0.001)$ & $(0.001)$ & $(0.0004)$ \\
& & & & & $-0.001^{* * *}$ \\
$x_{c, t}$ & & & & & $(0.00001)$ \\
& & & & & \\
\hline Year f.e. & $\checkmark$ & $\checkmark$ & $\checkmark$ & $\checkmark$ & $\checkmark$ \\
Amenity f.e. & $\checkmark$ & $\checkmark$ & $\checkmark$ & $\checkmark$ & $\checkmark$ \\
Cluster f.e. & & & & & \\
\hline Observations & 406,894 & 406,894 & 406,894 & 406,894 & $1,627,576$ \\
Adjusted $R^{2}$ & 0.447 & 0.105 & 0.070 & 0.278 & 0.168 \\
Residual Std. Error & 2.387 & 2.682 & 1.877 & 2.088 & 2.428 \\
\hline \hline Note: & \multicolumn{5}{c}{${ }^{*} \mathrm{p}<0.1 ;{ }^{* *} \mathrm{p}<0.05 ;{ }^{* * *} \mathrm{p}<0.01$} \\
\end{tabular}

Table 1 (1)-(4) shows the result of each year, while column (5) shows the result of pooled 
regression. When we check the effect of relatedness on the intensive margin of clusters, the unit of analysis used is the pair of "cluster-amenity." Table 1 (1) and (2) show that the relatedness has a positive and significant effect on the intensive margin before the outbreak of COVID-19. This means that a higher level of relatedness of amenity $a$ in a cluster will lead to an increase in the number of stores that provide the amenity in the cluster during normal periods in the next year. However, according to Table 1 (3) and (4), this positive role of relatedness is not working during the pandemic period. The other control variable, the number of stores in the amenity in the

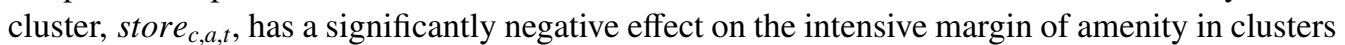
consistently. This result tells us that stores that provide the same amenity are competitors, while stores that provide related amenities can provide supplementary utility to a store. Table 1 (5) shows us that the effect of relatedness holds across the overall period when we control for the amenity and cluster fixed effects, as well as year fixed effect. However, as we can notice from Table 1 (3) and (4), during the pandemic period, relatedness is not working well for the increase in number of stores in a cluster. In fact, it tells us that checking the intensive margin during the abnormal period is not meaningful. Therefore, we will check the effect of relatedness on the survival of individual stores during the pandemic period in the next chapter.

\subsection{Shop level analysis: can more related amenities around individual stores help them survive?}

In this chapter, we look at individual stores that survived during the pandemic period. Our latest store location data contains stores that are operating as on June 30, 2021. Therefore, we look at individual stores with checking whether they have survived until the end of June in 2021.

Can more related amenities around individual stores help them survive? We formalize this question using multivariate logistic regression that predicts the 2-year survival rate survival ${ }_{i, c, a, r, 2021}$ of individual store $i$ in cluster $c$ and region $r$ while controlling for mixed effects: amenity fixed effect and cluster random effect. We choose the fixed effect model to control for the time invariant idiosyncratic characteristic of amenity (in large-level classification), because the effect associated with the characteristics of amenity is similar between sample and population. For example, different characteristics between restaurant business and selling clothes are fixed for both sample and population. On the other hand, we choose the random effect model to control for the time-invariant idiosyncratic characteristic of the cluster, since we detect the cluster and the effect can be changed when we try to find clusters with data belonging to a different year or city. Cluster level can be regarded as the fixed level but here we choose the random effect to estimate the effect with conservative restriction for our main result described in Equation 6 and Table 2 .

$$
\begin{aligned}
\text { survival }_{i, c, a, r, 2021} & =\beta_{0}+\beta_{1} \omega_{c, a, 2019}+\beta_{2} \text { store }_{c, a, 2019}+\beta_{3} \text { totalstore }_{c, 2019} \\
& +\beta_{4} \text { numBiz }_{r, 2019}+\beta_{5} \text { employment }_{r, 2019} \\
& +\beta_{6} \text { population }_{r, 2019}+\beta_{7} \text { popDensity }_{r, 2019}+\beta_{8} \text { agingIndex }_{r, 2019}+\beta_{9} \text { lowIncome }_{r, 2019} \\
& +\mu_{c}+\eta_{a}+\varepsilon_{c, a, 2019}
\end{aligned}
$$

where survival ${ }_{i, c, a, r, 2021}$ is a binary variable that indicates whether store $i$ has survived until June 30, 2021. Our main variable of interest is $\omega_{c, a, 2019}$, which is store $i$ 's density of related amenity in cluster $c$. We control for the number of competitors and size of the cluster by adding store $_{c, a, 2019}$, which is the number of stores that provide the same amenity as that of store $i$ in 2019, and totalstore $_{c, 2019}$, which is the total number of stores in the cluster $c$ that represent the size of cluster. The next line consists of control variables that are associated with overall economic vitality, 
that is, total number of establishments, numBizr,2019, and total employees in the establishment in region $r$ at dong-level, employment ${ }_{r, 2019}$. We also control for the demographic characteristics of regions (at dong-level) where the store $i$ located by adding the number of population of region $\mathrm{r}$, population pol, $_{r, 19}$, population density of region $r$, popDensity ${ }_{r, 2019}$, aging index that is defined as the percentage of people over 65 years old compared to the number of people below 14 years old in region $r$ at year 2019, agingIndex $x_{r, 2019}$, and the share of low income groups who are supported by the government. Again, we control for the amenity fixed effects (using large-level classification) and cluster random effects.

Table 2. Survival of amenity stores after the outbreak of COVID-19

\begin{tabular}{|c|c|c|c|c|c|c|c|}
\hline & \multicolumn{7}{|c|}{ Dependant variable: survival ${ }_{i, c, a, r, 2021}$} \\
\hline & (1) & (2) & (3) & (4) & (5) & (6) & (7) \\
\hline$\omega_{c, a, 2019}$ & $\begin{array}{l}0.0286^{* * * *} \\
(0.0027)\end{array}$ & $\begin{array}{c}0.0250^{* * * *} \\
(0.0027)\end{array}$ & $\begin{array}{c}0.0250^{* * * *} \\
(0.027)\end{array}$ & $\begin{array}{c}0.0236^{* * * *} \\
(0.0027)\end{array}$ & $\begin{array}{c}0.0242^{* * *} \\
(0.0027)\end{array}$ & $\begin{array}{c}0.0236^{* * * *} \\
(0.0027)\end{array}$ & $\begin{array}{c}0.0237^{* * * *} \\
(0.0027)\end{array}$ \\
\hline store $_{c, a, 2019}$ & & $\begin{array}{c}0.0011^{* * * *} \\
(0.0001)\end{array}$ & & $\begin{array}{c}0.0012^{* * * *} \\
(0.0001)\end{array}$ & $\begin{array}{l}0.0011^{* * *} \\
(0.0001)\end{array}$ & $\begin{array}{l}0.0012^{* * *} \\
(0.0001)\end{array}$ & $\begin{array}{l}0.0012^{* * *} \\
(0.0001)\end{array}$ \\
\hline totalstore $e_{c, 2019}$ & & & $\begin{array}{c}0.0011^{* * *} \\
(0.0001)\end{array}$ & & & & \\
\hline numBiz $_{r, 2019}$ & & & & $\begin{array}{c}-2.85 \cdot 10^{-5} * * * \\
\left(2.66 \cdot 10^{-6}\right)\end{array}$ & & $\begin{array}{l}-0.00003^{* * *} \\
\left(2.76 \cdot 10^{-6}\right)\end{array}$ & $\begin{array}{l}-0.00002^{* * *} \\
\left(2.79 \cdot 10^{-6}\right.\end{array}$ \\
\hline employment $_{r, 2019}$ & & & & & $\begin{array}{c}-2.51 \cdot 10^{-6 * * *} \\
\left(2.92 \cdot 10^{-7}\right)\end{array}$ & & \\
\hline $\log$ population $_{r, 2019}$ & & & & & & $\begin{array}{l}-0.0127 \\
(0.0083)\end{array}$ & $\begin{array}{l}-0.00001 \\
(0.0001)\end{array}$ \\
\hline $\operatorname{logpopDensity~}_{r, 2019}$ & & & & & & $\begin{array}{c}0.0006 \\
(0.0076)\end{array}$ & $\begin{array}{l}0.00007 \\
(0.0001)\end{array}$ \\
\hline agingIndex $_{r, 2019}$ & & & & & & & $\begin{array}{c}0.0001^{*} \\
(0.00006)\end{array}$ \\
\hline lowIncome $r, 2019$ & & & & & & & $\begin{array}{l}-0.0001 \\
(0.0001)\end{array}$ \\
\hline Amenity f.e. & $\checkmark$ & $\checkmark$ & $\checkmark$ & $\checkmark$ & $\checkmark$ & $\checkmark$ & $\checkmark$ \\
\hline Cluster r.e. & $\checkmark$ & $\checkmark$ & $\checkmark$ & $\checkmark$ & $\checkmark$ & $\checkmark$ & $\checkmark$ \\
\hline observation & 276804 & 276804 & 276804 & 276804 & 276804 & 276804 & 276804 \\
\hline log likelihood & -156496.17 & -156440.88 & -156440.88 & -156383.93 & -156404.02 & -156383.31 & -156380.54 \\
\hline
\end{tabular}

Table 2 shows our main result that explains the effect of relatedness on the survival of individual stores. We only look at stores that have been operated at least from 2017 to 2019 and check their survival at June 30, 2021. The positive effect of amenity relatedness on the survival of store is consistently significant over all columns and the coefficient are stable and consistent, which means that store collocated with more related amenities in their cluster is more likely to survive during the pandemic. Because of high correlation between the number of stores that provide the same amenity and total number of stores in the cluster, we control for those control variables separately in column (2) and (3). Interestingly, when we control the cluster fixed effect and amenity random effect, a store near higher number of stores that provide the same amenity (i.e., competitor) (column (2)) and a store in the bigger cluster in terms of total number of stores (column (3)) is likely to have a higher survival rate during the pandemic. In column (4) and (5), we control for the total number of establishments and the total number of employees in region $r$, which the store $i$ belongs to. Being different from column (2) and (3), all the enterprises in the region negatively affect the survival rate of stores in the same region. The demographic factors such as population, and population density do not have an effect on the survival rate of stores, while higher level of aging index is likely to increase the survival rate of the store. The share of low income, which may represents the purchasing power of the region, shows the negative effect 
but the effect is not significant.

\subsection{Cox proportional hazards model}

To check the robustness of our main results, we use the Cox proportional-Hazards model (Cox. 1972, Cox and Oakes, 2018) with a similar empirical specification to Equation 6. The Cox proportional-hazards model is widely used, especially in medical research for estimating the survival/death rate of patients. In our study, we look at the death rate of individual stores instead of patients.

We select stores that are open at least in 2016 and have been open in June 2019. By focusing on the long-run operated stores, we aim to see how hoarsely COVID-19 hit amenity stores and how the relatedness helps their survival. The number of stores that have been open during the period 2016-2019 is 221470. Among them, 22268 stores are closed by June 2020, and more 52014 stores are closed by June 2021.

Table 3. Cox proportional hazards model for stores that are opened at least in 2016 and have been open in June 2019. We estimate the death rate of each store with Cox mixed-effects model.

\begin{tabular}{|c|c|c|c|c|}
\hline & \multicolumn{4}{|c|}{ Dependent variable: Death probability } \\
\hline & (1) & (2) & (3) & (4) \\
\hline omega & $\begin{array}{c}-0.0186^{* * *} \\
(0.0022)\end{array}$ & $\begin{array}{c}-0.0164^{* * *} \\
(0.0021)\end{array}$ & $\begin{array}{c}-0.0162^{* * *} \\
(0.0022)\end{array}$ & $\begin{array}{c}-0.0144^{* * *} \\
(0.0024)\end{array}$ \\
\hline numstore & & $\begin{array}{c}-0.0004^{* * *} \\
(0.0001)\end{array}$ & $\begin{array}{c}-0.0004^{* * *} \\
(0.0001)\end{array}$ & $\begin{array}{c}-0.0004^{* * *} \\
(0.0001)\end{array}$ \\
\hline num biz & & $\begin{array}{c}0.00002^{* * *} \\
(0.0000)\end{array}$ & $\begin{array}{c}0.00002^{* * *} \\
(0.0000)\end{array}$ & $\begin{array}{r}0.00002^{* * *} \\
(0.0000)\end{array}$ \\
\hline $\log$ population & & & $\begin{array}{l}-0.0242 \\
(0.0150)\end{array}$ & $\begin{array}{c}-0.0309 \\
(0.0228)\end{array}$ \\
\hline population density & & & $\begin{array}{c}0.0590^{* * *} \\
(0.0106)\end{array}$ & $\begin{array}{c}0.0957^{* * *} \\
(0.0135)\end{array}$ \\
\hline aging index & & & & $\begin{array}{c}0.0002 \\
(0.0001)\end{array}$ \\
\hline low income & & & & $\begin{array}{l}-0.00005 \\
(0.00004) \\
\end{array}$ \\
\hline Amenity f.e. & $\checkmark$ & $\checkmark$ & $\checkmark$ & $\checkmark$ \\
\hline Cluster r.e. & $\checkmark$ & $\checkmark$ & $\checkmark$ & $\checkmark$ \\
\hline observation & 221470 & 221470 & 218114 & 173390 \\
\hline log-likelihood & -869848.3 & -869827.4 & -852086.5 & -672654.8 \\
\hline
\end{tabular}

Table 3 shows the result of Cox proportional hazard model with mixed effects. We estimate the effect of relatedness on the death rate with controlling for mixed effects: fixed effect of amenity classification and random effect of cluster. As shown in Table 3, store with higher related amenities around them is less likely to die during the pandemic. The effect of other variables are similar with our previous result in Table 2. When we control for the mixed effects of amenity classification and clusters, store with higher number of stores that provide the same amenity is less likely to die and store with higher number of any kind of establishment is more likely to die. Population in the cluster does not make an effect of the death rate of stores, while higher population density in the region of a store is likely increase the death rate of the store. 


\section{Conclusion}

Amenity clusters that consist of coffee shops, restaurants, and other small businesses provide utility to urban life, and at the same time, jobs for people living in the city. Therefore, the economic resilience of the amenity cluster - how much the economy sustains its normality despite the exogenous shock to the economy - and the survival of individual stores became important issues, during the COVID-19 pandemic in early 2020.

This study examines the impact of relatedness on the expansion of clusters and on the survival of individual stores during the COVID-19 pandemic. Our results show that (i) clusters are more likely to increase the number of stores that provide amenity $a$, when they already have the related amenity, but this effect is not working well during the pandemic. (ii) When we look at the survival rate of individual stores, stores are more likely to survive, when they are collocated with stores that provide related amenities in the same cluster. These results are supported by our robustness check using the Cox proportional-hazards model.

Our research is limited to showing the micro-mechanism of relatedness among amenity stores, and have not examined the source of relatedness empirically. However, considering that we controlled for idiosyncratic factors of cluster and amenity classification at large level, and we calculated the relatedness measure by looking at the small level classification of amenity, our results capture general phenomena associated with behavior of consumers. Consumer may more often visit places more where they can enjoy a variety of amenities but they can get a higher level of utility when they are provided related variety compared to unrelated variety. For example, hypothetically, if people visit a place to have a Korean style dinner, they can get higher utility when they can choose from Korean supper, Korean barbecue, Korean style seafood and etc. Hypothetically, if a person visits the hospital, they might find higher utility if they can easily visit the heath supplement store or pharmacy.

Despite our limitations, our results provide some light in the quest to understand regional economic resilience, by looking at the survival of important economic agent in a city, during the COVID-19 pandemic era. Our result suggests that looking at the various types of variety in economic structure should be one of the avenues for future research on regional resilience.

\section{Acknowledgement}

We thank to Jinsu Park for help with data. This project is funded by the National Research Foundation of Korea (NRF-2020R1F1A1072673). We also acknowledge the support of the Inha University. 


\section{References}

Balassa, B., 1965. Trade liberalisation and "revealed" comparative advantage. Manchester School 33, 99-123.

Balland, P.A., Boschma, R., Crespo, J., Rigby, D.L., 2019. Smart specialization policy in the european union: relatedness, knowledge complexity and regional diversification. Regional Studies 53, 1252-1268.

Boschma, R., Balland, P.A., Kogler, D.F., 2015. Relatedness and technological change in cities: the rise and fall of technological knowledge in us metropolitan areas from 1981 to 2010. Industrial and corporate change 24, 223-250.

Boschma, R., Minondo, A., Navarro, M., 2013. The emergence of new industries at the regional level in Spain: A proximity approach based on product relatedness. Economic Geography 89, 29-51.

Christopherson, S., Michie, J., Tyler, P., 2010. Regional resilience: theoretical and empirical perspectives. Cambridge journal of regions, economy and society 3, 3-10.

Cowell, M.M., 2013. Bounce back or move on: Regional resilience and economic development planning. Cities 30 , 212-222.

Cox, D.R., 1972. Regression models and life-tables. Journal of the Royal Statistical Society: Series B (Methodological) 34, 187-202.

Cox, D.R., Oakes, D., 2018. Analysis of survival data. Chapman and Hall/CRC.

Doran, J., Fingleton, B., 2018. Us metropolitan area resilience: insights from dynamic spatial panel estimation. Environment and Planning A: Economy and Space 50, 111-132.

Evans, R., Karecha, J., 2014. Staying on top: Why is munich so resilient and successful? European Planning Studies 22 , 1259-1279.

Frenken, K., Van Oort, F., Verburg, T., 2007. Related variety, unrelated variety and regional economic growth. Regional Studies 41, 685-697.

Gao, J., Jun, B., Pentland, A., Zhou, T., Hidalgo, C.A., 2017. Collective learning in China's regional economic development. arXiv:1703.01369

Glaeser, E.L., Ponzetto, G.A., Tobio, K., 2014. Cities, skills and regional change. Regional Studies 48, 7-43.

Hidalgo, C.A., Balland, P.A., Boschma, R., Delgado, M., Feldman, M., Frenken, K., Glaeser, E., He, C., Kogler, D.F., Morrison, A., et al., 2018. The principle of relatedness, in: International Conference on Complex Systems, Springer. pp. $451-457$.

Hidalgo, C.A., Castañer, E., Sevtsuk, A., 2020. The amenity mix of urban neighborhoods. Habitat International 106, 102205.

Hidalgo, C.A., Klinger, B., Barabási, A.L., Hausmann, R., 2007. The product space conditions the development of nations. Science 317,482 .

Jacobs, J., et al., 1970. The Economy of Cities. London: Jonathan Cape.

Jara-Figueroa, C., Jun, B., Glaeser, E.L., Hidalgo, C.A., 2018. The role of industry-specific, occupation-specific, and location-specific knowledge in the growth and survival of new firms. Proceedings of the National Academy of Sciences $115,12646-12653$.

Jun, B., Alshamsi, A., Gao, J., Hidalgo, C.A., 2020. Bilateral relatedness: knowledge diffusion and the evolution of bilateral trade. Journal of Evolutionary Economics 30, 247-277.

Kim, S.H., Jun, B., Lee, J.D., 2021. Technological relatedness: How do firms diversify their technology? . 
Kogler, D.F., Rigby, D.L., Tucker, I., 2013. Mapping knowledge space and technological relatedness in US cities. European Planning Studies 21, 1374-1391.

Martin, R., Sunley, P., 2015. On the notion of regional economic resilience: conceptualization and explanation. Journal of Economic Geography 15, 1-42.

Neffke, F., Henning, M., Boschma, R., 2011. How do regions diversify over time? Industry relatedness and the development of new growth paths in regions. Economic Geography 87, 237-265.

Rigby, D.L., 2015. Technological relatedness and knowledge space: Entry and exit of us cities from patent classes Regional Studies 49, 1922-1937.

Saxenian, A., 1996. Regional Advantage: Culture and Competition in Silicon Valley and Route 128. Cambridge: Harvard University Press.

Simmie, J., Martin, R., 2010. The economic resilience of regions: towards an evolutionary approach. Cambridge journal of regions, economy and society 3, 27-43.

Yang, Y., Diez-Roux, A.V., 2012. Walking distance by trip purpose and population subgroups. American Journal of Preventive Medicine 43, 11-19. 


\section{Appendix A. Correlation Matrix}

Appendix .1. cluster level analysis

Table .4. Summary statistics for cluster level analysis

\begin{tabular}{lccccc}
\hline \hline Statistic & $\mathrm{N}$ & Mean & St. Dev. & Min & Max \\
\hline omega & $1,627,576$ & 13.168 & 4.472 & 0.000 & 93.880 \\
numStore & $1,627,576$ & 0.975 & 5.277 & 0 & 1,206 \\
totalNum & $1,627,576$ & 758.817 & 431.787 & 54 & 3,127 \\
\hline
\end{tabular}

Table .5. Correlation Matrix for cluster level analysis

\begin{tabular}{cccc}
\hline \hline & omega & numStore & totalNum \\
\hline omega & 1 & & \\
numStore & 0.130 & 1 & \\
totalNum & 0.579 & 0.105 & 1 \\
\hline
\end{tabular}


Appendix .2. store level analysis

Table .6. Summary statistics for store level analysis

\begin{tabular}{lccccc}
\hline \hline Statistic & $\mathrm{N}$ & $\mathrm{Mean}$ & St. Dev. & Min & Max \\
\hline omega_2019 & 766,835 & 15.754 & 3.928 & 1.610 & 87.350 \\
numStore_2019 & 766,835 & 28.637 & 54.438 & 0 & 620 \\
totalNum_2019 & 766,835 & 28.637 & 54.438 & 0 & 620 \\
numBiz_2019 & 765,782 & $3,463.072$ & $3,503.021$ & 7.000 & $16,620.000$ \\
employee_2019 & 765,782 & $25,378.500$ & $35,338.630$ & 17.000 & $170,474.000$ \\
logpop & 760,158 & 9.965 & 0.584 & 5.5910 & 10.964 \\
logden & 759,127 & 9.801 & 0.699 & 5.652 & 10.960 \\
\hline
\end{tabular}

Table .7. Correlation matrix for store level analysis

\begin{tabular}{|c|c|c|c|c|c|c|c|c|c|}
\hline & omega_2019 & numStore_2019 & totalNum_2019 & numBiz_2019 & employee_2019 & logpop & logden & agingindex_2020 & totallowincome \\
\hline omega_2019 & 1 & & & & & & & & \\
\hline numStore_2019 & -0.033 & 1 & & & & & & & \\
\hline totalNum_2019 & -0.033 & 1 & 1 & & & & & & \\
\hline numBiz_2019 & -0.129 & 0.205 & 0.205 & 1 & & & & & \\
\hline employee_2019 & -0.042 & 0.106 & 0.106 & 0.884 & 1 & & & & \\
\hline logpop & 0.169 & -0.204 & -0.204 & -0.198 & -0.105 & 1 & & & \\
\hline logden & 0.205 & -0.146 & -0.146 & -0.411 & -0.452 & 0.455 & 1 & & \\
\hline agingindex_2020 & -0.076 & 0.193 & 0.193 & 0.387 & 0.161 & -0.598 & -0.302 & 1 & \\
\hline totallowincome & 0.096 & -0.098 & -0.098 & -0.080 & -0.168 & 0.336 & 0.226 & 0.216 & 1 \\
\hline
\end{tabular}

